\title{
Functional scoliosis caused by leg length discrepancy
}

Jan W. Raczkowski, Barbara Daniszewska, Krystian Zolynski

$1^{\text {st }}$ Department of Orthopaedics and Rehabilitation, Medical University of Lodz, Lodz, Poland

Submitted: 5 September 2009

Accepted: 6 December 2009

Arch Med Sci 2010; 6, 3: 393-398

DOI: 10.5114/aoms.2010.14262

Copyright $\odot 2010$ Termedia \& Banach

\section{Abstract}

Introduction: Leg length discrepancy (LLD) causes pelvic obliquity in the frontal plane and lumbar scoliosis with convexity towards the shorter extremity. Leg length discrepancy is observed in 3-15\% of the population. Unequalized lower limb length discrepancy leads to posture deformation, gait asymmetry, low back pain and discopathy.

Material and methods: In the years 1998-2006, 369 children, aged 5 to 17 years (209 girls, 160 boys) with LLD-related functional scoliosis were treated. An external or internal shoe lift was applied.

Results: Among 369 children the discrepancy of $0.5 \mathrm{~cm}$ was observed in 27, $1 \mathrm{~cm}$ in $329,1.5 \mathrm{~cm}$ in 9 and $2 \mathrm{~cm}$ in 4 children. During the first follow-up examination, within 2 weeks, the adjustment of the spine to new static conditions was noted and correction of the curve in 316 examined children (83.7\%). In 53 children (14.7\%) the correction was observed later and was accompanied by slight low back pain. The time needed for real equalization of limbs was 3 to 24 months. The time needed for real equalization of the discrepancy was 11.3 months.

Conclusions: Leg length discrepancy equalization results in elimination of scoliosis. Leg length discrepancy $<2 \mathrm{~cm}$ is a static disorder; that is why measurements should be performed in a standing position using blocks of adequate thickness and the position of the posterior superior iliac spine should be estimated.

Key words: leg length discrepancy, functional scoliosis, low back pain.

\section{Introduction}

Limb length discrepancy (LLD) causes pelvic obliquity in the frontal plane [1-9]. Quite rigid junction of $L_{5}$ vertebra with sacral bone results in lumbar scoliosis with convexity directed towards the short extremity (Figure 1). Later, unequalized length discrepancy of lower limbs leads to posture deformation, gait asymmetry, low back pain, discopathy as well as gonarthrosis, coxarthrosis and hip flexion contracture on the side of the longer extremity or ankle joint contracture in the equinal position on the side of the shorter extremity [3-5]. In sporadic cases LLD can be secondary in relation to scoliosis, particularly in the case of compensatory scoliosis. In these cases LLD appears as the result of asymmetrical load of lower extremities $[8,9]$.

The aim of the study was to assess the possibility of correction of spine functional curvature and potential real equalization of LLD.

Limb length discrepancy is usually not large (about $1 \mathrm{~cm}$ ) and is observed in about $3-15 \%$ of the population. The reasons for the occurrence of such a difference are not known in $95 \%$ of cases $[1,4,10]$. Two basic groups should be distinguished from among the known reasons: the

\author{
Corresponding author: \\ Jan Raczkowski, MD, PhD \\ $1^{\text {st }}$ Department \\ of Orthopaedics \\ and Rehabilitation \\ Medical University of Lodz \\ 113 Żeromskiego Str. \\ 90-549 Lodz, Poland \\ E-mail: \\ jan.raczkowski@umed.lodz.pl
}



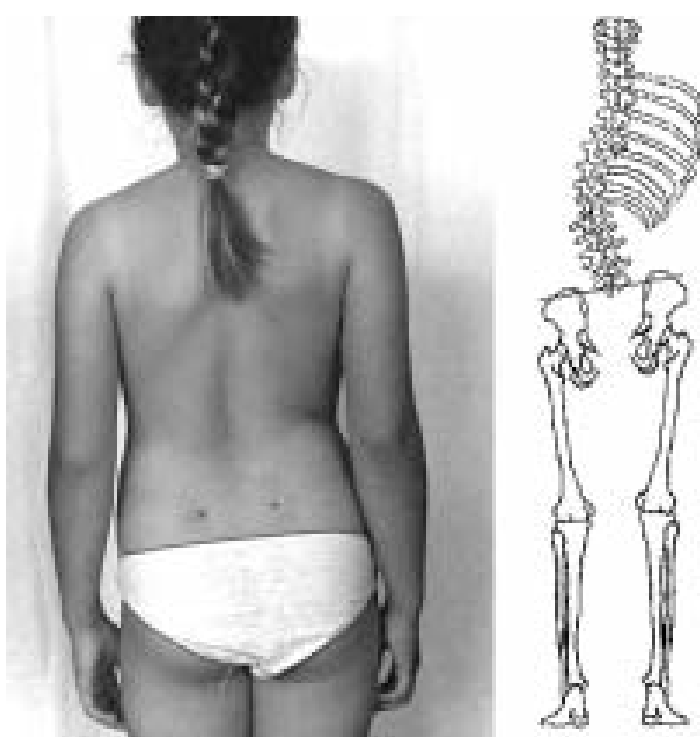

Figure 1. An 11-year old girl with lumbar scoliosis caused by LLD

processes directly causing the change of leg length and the processes causing asymmetrical growth [1, $4,10,11]$. The first group includes lower limb diaphysis fracture with incomplete union or growth disorders and congenital or acquired bone deformations and hip joint deformations, including iatrogenic, e.g. after hip joint alloplasty [12]. Group two comprises inhibition or stimulation of limb growth on one side. The inhibition of limb growth may result from an injury to the epiphysis, or may be related to paralysis, inflammation, ischaemia, tumours, necrosis or congenital deformation of extremities [13-17]. Stimulation of limb growth can also occur in the course of some tumours (haemangiomatosis, neurofibromatosis, fibrous dysplasia) as well as in the course of inflammatory processes and healing of fractures which cause increased blood flow to bone. Table I presents the classification of aetiology of LLD [15-17].

Scoliosis which develops due to leg length discrepancy is included within functional scolioses. This type of scoliosis regresses totally or partially when its cause, that is LLD, is removed (Figure 2).

Limb length equalization is not an easy task. It requires careful thinking and planning and an
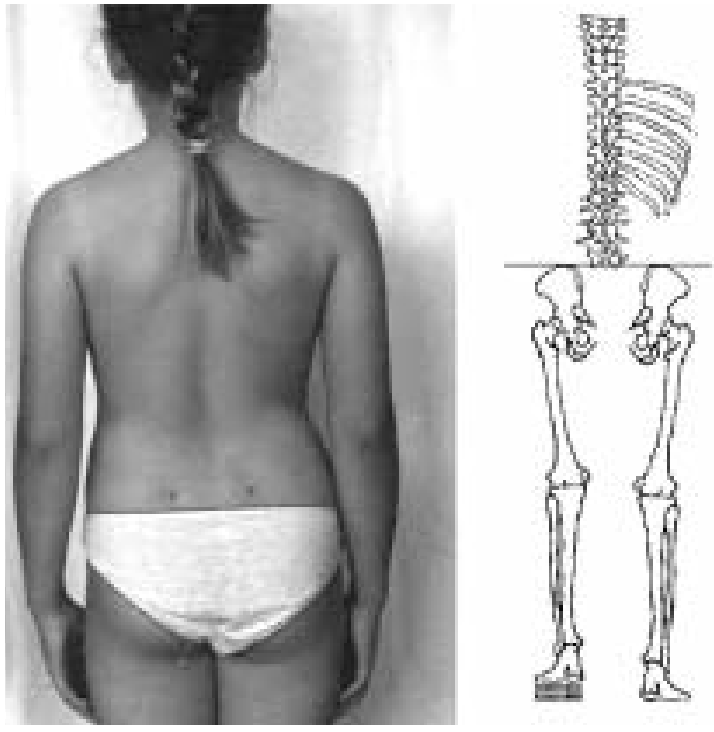

Figure 2. Equalization of curvature with a shoe lift

adequate strategy of management [4, 18-21]. The two most important factors that should be taken into account in planning are precisely measured length discrepancy and the patient's age. In many cases the causes of LLD development, prognosticated progress of the discrepancy and the patient's general and mental condition are essential factors in the selection of treatment options [18-21].

Leg length discrepancies $\leq 2 \mathrm{~cm}$ seldom cause a problem. Internal shoe lifts are added of a thickness corresponding with the discrepancy $[1,2,4]$. The most frequently used internal shoe lifts are of a thickness from $0.5-1.5 \mathrm{~cm}$. For LLD of $1.5-2 \mathrm{~cm}$ it is more comfortable for a patient to use an external heel lift. For discrepancies from 3 to $20 \mathrm{~cm}$ surgical equalization is suggested. Leg length discrepancies of $3-5 \mathrm{~cm}$ is usually treated with shortening of the longer limb by growth arrest (epiphysiodesis), by real shortening of the bone or by corrective asymmetry. Leg length discrepancies in the range $6-15 \mathrm{~cm}$ requires lengthening of the shorter limb with external fixators. The treatment of LLD > $15 \mathrm{~cm}$ demands combined treatment by lengthening the shorter and shortening the longer limb. Surgical treatment of LLD $>20 \mathrm{~cm}$ does not

Table I. The causes of development of LLD

\begin{tabular}{|c|c|}
\hline Causes of direct change of leg length & Causes of asymmetrical growth of extremities \\
\hline $\begin{array}{l}\text { A. Traumas: fractures, amputations } \\
\text { B. Growth disorders } \\
\text { C. Congenital or acquired deformations } \\
\text { of bones and joints }\end{array}$ & $\begin{array}{l}\text { A. Inhibition of growth: congenital, injury to physis, paralysis, } \\
\text { bone inflammatory process, tumours (destroying growth cartilage } \\
\text { or application of radiation in the course of treatment), ischaemia } \\
\text { B. Stimulation of growth: tumours, inflammatory processes } \\
\text { and fractures (in the process of healing), increased blood flow } \\
\text { C. Unknown }\end{array}$ \\
\hline
\end{tabular}


Table II. Treatment options for LLD depending on the discrepancy level (acc. to Dahl, 1996 - modified)

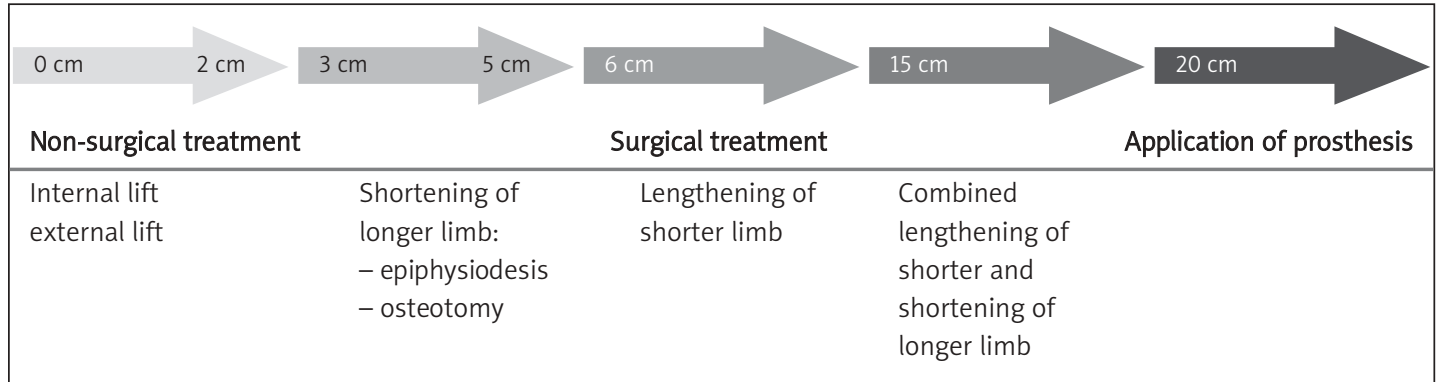

give much chance for limb length equalization. In these cases external prostheses are used. In the case when not total equalization is obtained after surgery the discrepancy should be equalized with an internal or external heel lift [12, 20-22]. The methods of management depending on LLD magnitude are presented in Table II.

The patient's age is the second most important factor taken into account in selecting the treatment options. In children and adolescents who have not stopped growing there is a possibility to use compensatory and developmental mechanisms of the organism. The applied non-surgical (internal/external shoe lift) or surgical methods (epiphysiodesis) are based on possible stimulation or inhibition of limb growth. In subjects who have completed growth non-surgical treatment can be applied in the form of external equalization of the asymmetry. However, permanent correction, not always total, can be obtained in such cases only owing to surgical treatment through lengthening or shortening [1, 18, 19, 23-25].

\section{Material and methods}

Retrospective observational study. In the years 1998-2006, 369 children, aged from 5 to 17 years, with functional scoliosis caused by LLD were treated in the Centre of Rehabilitation for Children and Adolescents, Medical University of Lodz, Poland. The children were sent to our centre by primary care physicians and apart from slight LLD these children did not demonstrate any other disorders. Healed fractured diaphysis was found in 12 children. In 8 cases the fracture caused lengthening and in 4 shortening of the fractured extremity. The leg length discrepancy was from $0.5 \mathrm{~cm}$ to $2 \mathrm{~cm}$. Children with discrepancy $>2 \mathrm{~cm}$ were excluded from this study because they required different management, including surgery. Children in whom LLD resulted from neurological or muscular reasons were also excluded. Among the children treated in the centre, there were 209 girls and 160 boys, 57\% and 43\%, respectively. All children were treated with an internal shoe lift. Only in 4 cases were external heel lifts applied. The thickness of the internal shoe lift (or external heel lift) was selected by measuring the discrepancy with blocks of thickness from $0.5 \mathrm{~cm}$ to $2 \mathrm{~cm}$. Equal position of posterior superior iliac spines decided on the final selection of the lift thickness. The position of anterior superior iliac spines is not reliable due to asymmetric development of the iliac alae. The children had a follow-up examination 2 weeks after application of the shoe lift in which correction of the spine and occurrence of pain were assessed. Corrective (symmetrical, strengthening postural muscles) and autocorrective exercises, preceded by sollux lamp irradiation (IR $20 \mathrm{~min}$ ), and sodium diclofenac were applied in those patients in whom the correction of the curve was observed to be incomplete. The next follow-up examinations were performed every 3 months until equalization of the extremities or growth completion by the patient. The last followup examination was performed 3 months after limb equalization and removal of the shoe lift.

Static load of extremities was measured in all children on an electronic balance specially

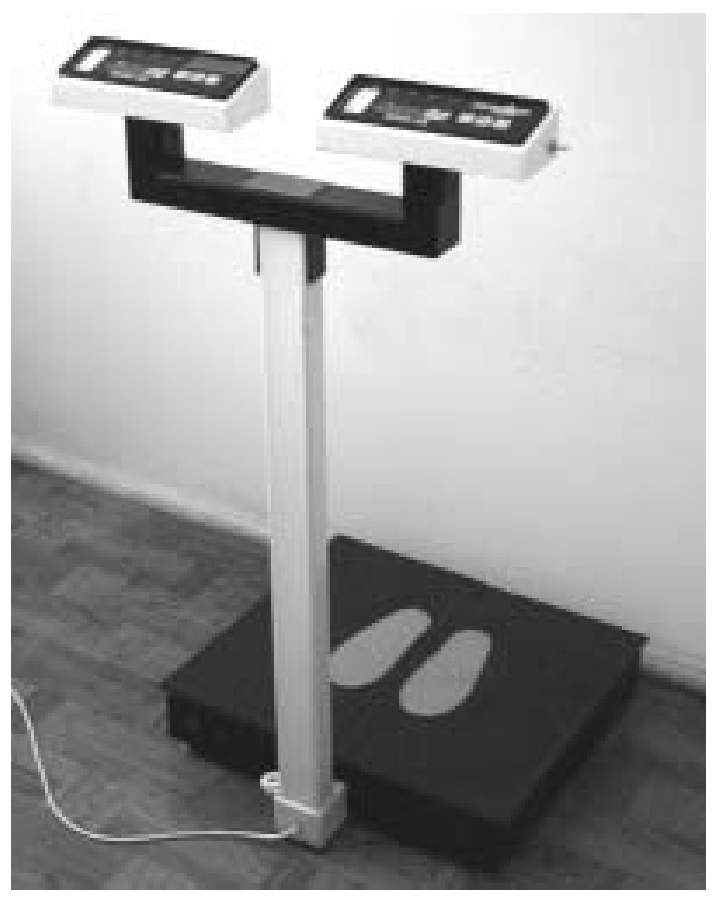

Figure 3. Electronic balance specially constructed for this research 
Table III. Length discrepancy and number of children

\begin{tabular}{|ccc|}
\hline Length discrepancy & Number of children & $\%$ \\
\hline 0.5 & 27 & 7.3 \\
\hline 1.0 & 329 & 89.1 \\
\hline 1.5 & 9 & 2.4 \\
\hline 2.0 & 4 & 1.2 \\
\hline
\end{tabular}

constructed for this purpose (Figure 3). The measurement was performed directly after LLD diagnostication and determination of its size - first without the shoe lift and then with it. During the first measurement and after LLD equalization the height was measured.

\section{Results}

Among 369 children the discrepancy of $0.5 \mathrm{~cm}$ was observed in 27 children, $1 \mathrm{~cm}$ in $329,1.5 \mathrm{~cm}$ in 9 and $2 \mathrm{~cm}$ in 4 children (Table III).

On admission, age of the investigated children was in the range 5-17 years, mean 12.3, with standard deviation $S D=3.03$ (Table IV). Among the treated children and adolescents the shortening concerned the left lower limb in 317 cases (86\%), 180 in girls and 137 in boys. Shorter right lower limb was observed in 29 girls and 23 boys, together in 52 (14\%). During the first follow-up examination, within 2 weeks, the adjustment of the spine to new static conditions was noted and correction of the curve in 316 examined children (83.7\%). In 53 children (14.7\%) the correction was observed later and

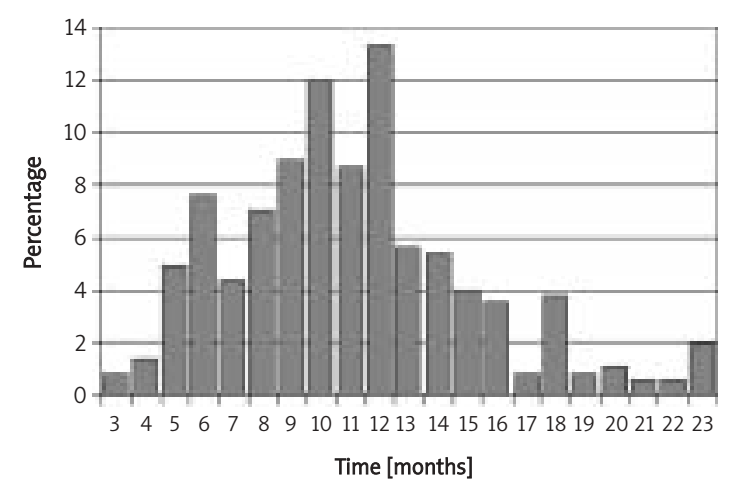

Figure 4. Percentage of children with equalized LLD depending on the time of shoe lift application was accompanied by slight low back pain. The time needed for leg length equalization was from 3 to 24 months - mean 10.8, with standard deviation $S D=4.32$. In $80 \%$ of cases the equalization occurred between 8 and 16 months of shoe lift application (Figure 4).

Mean time needed for $1 \mathrm{~cm}$ equalization was about 11.3 months, SD = 5.0 (Table IV). In 16 children $(4.2 \%)$ total leg length equalization was not obtained due to earlier growth completion.

In 11 children (3\%), a few years after the treatment termination, LLD occurred again and involved the same extremity. Repeated occurrence of LLD was observed in the period of growth stimulation in puberty. In 2 of these children no total equalization of LLD was reached again due to their completion of the growth process.

The measurements of static load of lower extremities pointed to increased load of the longer limb from $5 \%$ to $28 \%$, mean $12.5 \%$, standard deviation $S D=6.1$. The measurements performed directly after internal shoe lift application demonstrated increased load of the limb with a lift from $5 \%$ to $41 \%$, mean $22 \%$, $S D=8.7$.

The difference in growth in children before shoe lift application and after LLD equalization was from $4 \mathrm{~cm}$ to $9 \mathrm{~cm}$, mean $5.9 \mathrm{~cm}, S D=1.2$.

\section{Discussion}

Leg length discrepancy $>3 \mathrm{~cm}$ causes distinct gait and posture disorders - the bigger the difference the greater and more distinct are the disorders. The frequency of their occurrence is equal to the frequency of occurrence of their causes. However, a slight leg length discrepancy, of up to $2 \mathrm{~cm}$, is quite frequent. In screening examinations performed in the years 1992-2002 by the staff of the Centre of Rehabilitation for Children and Adolescents, LLD was found in about $10 \%$ of the population of children from primary schools. Stricker and Hunt reported the prevalence of LLD in adults at the level of about $15 \%$. The reasons for its occurrence are unknown in about 95\% $[6,15,26]$.

Precise determination of LLD is an important problem. The widely used method of assessing the discrepancy is the measurement of the distance from the anterior superior iliac spine to the medial malleolus with a measuring tape. This is a comfortable and relatively simple way applied

Table IV. Period of real equalization

\begin{tabular}{|lcccc|}
\hline & Mean & Standard deviation & Variance & Variation coefficient \\
\hline Age & 12.35 & 3.03 & 9.20 & 24.6 \\
\hline Period of equalization in months & 10.81 & 4.32 & 18.68 & 40.0 \\
\hline $1 \mathrm{~cm}$ of equalization in months & 11.26 & 5.00 & 25.00 & 44.4 \\
\hline
\end{tabular}


together with $\mathrm{X}$-rays in planning the treatment of LLD $>2 \mathrm{~cm}$. Leg lenght discrepancy $<2 \mathrm{~cm}$ is a static disorder; that is why measurements should be performed in a standing position using blocks of adequate thickness and the position of the posterior superior iliac spine should be estimated [27].

Small leg length discrepancy is not felt by a child or adult and it does not result in distinct, noticeable disorders in gait parameters or the observed changes are insignificant. Thus, it is often neglected by the examining person. However, even such a small discrepancy causes pelvic obliquity in the frontal plane, which in turn causes scoliosis in the lumbar region. These changes are the result of asymmetry of spine static and dynamic load as well as intervertebral disc dislocation [24, 26, 28, 29]. Kowalik-Nitera found LLD in $71 \%$ of patients treated surgically due to lumbar discal hernia [30]. This fact proves the importance of the problem. In current literature (the last ten years) there have not been any studies concerning small discrepancies.

The carried out investigations demonstrate a significant increase in static load of the longer extremity on average by about $12.5 \%$. The increased load of the shorter limb directly after application of an internal shoe lift is even more distinct, on average $22 \%$. This phenomenon is associated with mechanisms compensating the posture including sense of equilibrium. The increase of load along the long axis causes stimulation of chondrocyte proliferation in the epiphyseal cartilage and stimulation of bone growth. On the other hand, the decrease of axial load inhibits bone growth [31-34]. The studies on athletes reported by Dahl, performed by Kawamura at the beginning of the 1980s, found LLD prevalence $>0.5 \mathrm{~cm}$ among $36 \%$ of the tested group (51 from among 141 sportsmen) [18]. In this group limb load asymmetry is distinct, particularly in technical competitions. Modulation of lower limb load enables equalization of lower limb discrepancy.

In conclusion, LLD is a frequent phenomenon, observed in $3-15 \%$ of the population. In the majority of cases its cause is unknown and its size is small, within $2 \mathrm{~cm}$. Even a slight LLD causes scoliosis in the lumbar region. Medical treatment requires application of external equalization in the form of an internal or external shoe lift throughout the period of about a year and regular follow-up examinations: the first after 2 weeks and then every 3 months until equalization of the discrepancy or completion of growth. Leg length discrepancy observed after growth completion requires permanent external equalization. The time needed for the equalization of limb length discrepancy depends on the growth rate. To obtain LLD equalization of $1 \mathrm{~cm}$ the child's growth should increase about $5-6 \mathrm{~cm}$. That is why LLD equalization was the fastest in the pubertal rapid growth.
Leg length discrepancy equalization results in elimination of functional scoliosis of the spine.

\section{References}

1. Aaron AD, Eilert ED. Results of Wagener and Ilizarov methods of limb-lengtening. J Bone Joint Surg A 1996; 78: 20-9.

2. D'Amico M. Scoliosis and leg asymmetries: a reliable approach to assess wedge solutions efficacy. Studies in health technology and informatics 2002; 88: 285-9.

3. tabaziewicz L, Nowakowski A. Scoliosis and faulty posture [Polish]. Chir Narz Ruchu Ortop Pol 1996; 61: 247-50.

4. Rose R. et al. Pediatric leg length discrepancy: causes and treatments. Orthop Nurs 1999; 18: 21-30.

5. Skwarcz A, Majcher P. Rehabilitation in scoliosis. In: Medical rehabilitation [Polish]. Urban \& Partner, Wrocław 2003; 185-237.

6. Stricker SJ, Hunt T. Evaluation of leg discrepancy in children. Int Pediatr 2004; 19: 134-42.

7. Walsh M. Leg length discrepancy - an experimental study of compensatory changes in three dimensions using gait analysis. Gait Posture 2000; 12: 156-61.

8. Young RS, Andrew PD, Cummings GS. Effect of simulating leg length inequality on pelvic torsion and trunk mobility. Gait Posture 2000; 11: 217-23.

9. Zabjek KF, Leroux MA, Coillard C, et al. Acute postural adaptation induced by shoe lift in idiopathic scoliosis patients. Eur Spine J 2001; 10: 107-13.

10. Enjolras O, Chapot R, Merland JJ. Vascular anomalies and the growth of limbs: a review. Orthopaedics 2004; 13: 349-57.

11. Breugem CC, Maas M, Breugem SJ, et al. Vascular malformations of the lower limb with osseous involvement. J Bone Joint Surg 2003; 85: 399-405.

12. Goldstein WM. Leg length inequality in total hip arthroplasty. Orthopedics 2005; 28: 1037-40.

13. Grzegorzewski A, Kozlowski P, Szymczak W, et al. Leg length discrepancy in Legg-Calve-Perthes disease. J Pediatr Ortop 2005; 25: 206-9.

14. Konyves A, Bannister GC. The importance of leg length discrepancy after total hip arthroplasty. J Bone Joint Surg 2005; 87: 155-7.

15. Raczkowski JW. Faulty postures in children from elementary schools. In: Antropology and Medicine [Polish]. University of Lodz 1996; 2: 291-300.

16. Shen FH, Samartzis D. Traumatic scoliosis. Lancet 2005; 365: 910.

17. Zarzycki D, Jasiewicz B, Kacki W, et al. Limb lengthening in fibular hemimelia type II: can it be an alternative to amputation? J Pediatr Ortop B 2006; 15: 147-53.

18. Dahl MT. Limb length discrepancy. Pediatr Clin N Am 1996; 43: 4.

19. Paley D, Bhave A, Herzenberg JE, Bowen JR. Multiplier method for predicting limb-length discrepancy. J Bone Joint Surg A 2000; 82: 1432-46.

20. Stanitski DF. Limb length discrepancy: an ortopaedic knowledge update. Pediatrics 1996; 185-93.

21. Stanitski DF. Limb length inequality: assessment and treatment options. J Am Acad Ortho Surg 1999; 7: 143-53.

22. Hasler CC. Leg length inequality. Indications for treatment and importance of shortening procedures. Der Orthopade 2000; 29: 766-74.

23. Mier R, Brower T. A guide for primary care physician. Pediat Orthoped 1994; 120-126. 
24. Bhave A, Paley D, Herzenberg JE. Improvement in gait parameters after lengthening for treatment of limb-lenght discrepancy. J Bone Joint Surg A 1999; 81: 529-34.

25. Beaudoin L, Zabjek KF, Leroux MA, Coillard C, Rivard CH. Acute systematic and variable postural adaptations induced by an orthopaedic shoe lift in control subjects. Eur Spine J 1999; 8: 40-5.

26. Gurney B. Leg length discrepancy. Gait Posture 2002; 15; 195-206.

27. Terry MA. Measurement variance in limb length discrepancy: clinical and radiographic assessment of interobserver and intraobserver variability. J Pediatr Orthop 2005; 25; 197-201.

28. Song KM, Halliday SE. The effect of limb length discrepancy on gait. J Bone Joint Surg 1997; 79: 1690-8.

29. Sundaramurthy S, Mao JJ. Modulation of endochondral development of the distal femoral condyle by mechanical loading. J Orthop Res 2006; 24: 229.

30. Nitera-Kowalik A. Thermographical evaluation of effectivness of rehabilitation excercises in patients after microsrugical treatment of lumbo-sacral spine. Medical University of Lodz 2004

31. Germiller JA, Goldstein SA. Structure and function embryonic growth plate in the asenc of functioning skeletal muscle. J Orthop Res 1997; 15: 362-70.

32. Heegaard JH, Beaupre GS, Carter DR. Mechanically modulated cartilage growth may regulate joint surface morphogenesis. J Orthop Res 1999; 174: 509-17.

33. McCarthy JJ, Kim H, Saluan P, Karsky D, Davidson RS. The effects of limb lengthening on growth. J Pediatr Ortop B 2003; 12: 328-31.

34. Vitale MA, et al. The effect of limb length discrepancy on health-related quality of life: is the ' $2 \mathrm{~cm}$ rule' appropriate? J Pediatr Ortop B 2006; 15: 1-5. 